\title{
As políticas de avaliação e responsabilização no Brasil: uma análise da Educação Básica nos estados da região Nordeste
}

\author{
Dalila Andrade Oliveira ${ }^{1}$ (D) @ \\ Ana Maria Clementino ${ }^{2}$ (D) @ \\ 1,2 Universidade Federal de Minas Gerais (UFMG), Brasil
}

Resumo. Este artigo analisa as políticas educacionais dos nove estados da região Nordeste do Brasil. A partir de estudos documentais, buscou-se estabelecer, por meio do método comparativo, algumas semelhanças e diferenças entre os programas e políticas dirigidos ao corpo docente e funcional, à gestão da escola e à avaliação. Os estudos documentais foram realizados no âmbito de uma pesquisa em desenvolvimento que busca compreender em que medida a Nova Gestão Pública tem sedimentado um modelo transnacional de privatização dos serviços públicos, em especial a educação. A análise aponta uma forte presença das políticas de avaliação como uma característica comum entre os estados como estratégia para a melhoria da educação, mas a forma de conduzi-las varia consideravelmente. Foram classificados em três diferentes grupos os estados de acordo com as formas de condução dessas políticas, a partir dos sistemas de responsabilização que desenvolvem.

Palavras-chave: política educacional; avaliação; responsabilização.

\section{Las políticas de evaluación y responsabilización en Brasil: un análisis de la Educación Básica en los estados de la región Nordeste}

Resumen. Este artículo analiza las políticas educativas de los nueve estados de la región Nordeste de Brasil. En base a estudios documentales, se ha buscado establecer por medio del método comparativo, algunas similitudes y diferencias entre los programas y políticas dirigidos al cuerpo docente y funcional, a la gestión escolar y a la evaluación. Se han realizado los estudios documentales en el ámbito de una investigación en desarrollo, que busca comprender en qué medida la Nueva Gestión Pública ha sedimentado un modelo transnacional de privatización en los servicios públicos, en especial la educación. El análisis apunta a una fuerte presencia de las políticas de evaluación como una característica común de los estados como estrategia para la mejora de la educación, pero la forma de conducirlas varía considerablemente. Se han clasificado los estados en tres grupos distintos según las formas de conducción de esas políticas y los sistemas de responsabilización que desarrollan.

Palabras clave: política educativa; evaluación; responsabilidad.

\begin{abstract}
Evaluation and accountability policies in Brazil: an analysis of Basic Education in the states of the Northeast region

Abstract. This article analyzes the educational policies of the nine states in the Northeast region of Brazil. Based on documentary studies, we sought to establish, through the comparative method, some similarities and differences between the programs and policies aimed at the teaching and functional staff, school management and evaluation. The documentary studies were carried out as part of a research in development that seeks to understand the extent to which the New Public Management has consolidated a transnational model of privatization of public services, especially education. The analysis points to a strong presence of evaluation policies as a common feature among states as a strategy for improving education, but the way to conduct them varies considerably. States were classified into three different groups according to the ways in which these policies are conducted, based on the accountability systems they develop.
\end{abstract}

Keywords: educational policy; evaluation; accountability. 


\section{Introdução}

A partir de estudos documentais, relativos às políticas educacionais dos nove estado da região Nordeste do país, buscamos analisar comparativamente as políticas que orientam a oferta da Educação Básica nas suas redes públicas de ensino. Destacamos os programas e políticas dirigidos aos docentes e funcionários, à gestão da escola e à avaliação.

O exercício da comparação e classificação é o coração da análise comparativa. Para tanto, a elaboração de tipologias é essencial. Generalizar é ganhar uma capacidade explicativa, mas é necessário saber que isso pode vir acompanhado de perda de precisão. Dessa forma, é necessário conceituar o "idêntico" e o que constitui o "diferente" (Gazibo \& Jensen, 2004). Construir categorias implica uma atividade de redução sobre a base de critérios precisos. Os elementos de contraste devem estar claramente identificados.

Sabendo do desafio que implica estabelecer comparações em contexto tão diversificado, já que esses estados possuem relativa autonomia para definir suas políticas educacionais, de acordo com a organização federativa do país, propomo-nos, apresentar uma análise sobre as políticas de educação em curso, apontando as tendências observadas. Os estudos documentais foram realizados no âmbito de uma pesquisa em desenvolvimento que busca compreender em que medida a Nova Gestão Pública tem sedimentado um modelo transnacional de privatização dos serviços públicos, em especial a educação. Este artigo apresenta resultados parciais da pesquisa, oriundos da revisão de literatura e de levantamento documental relativo ao contexto brasileiro.

O Brasil é o mais populoso país da América Latina, com cerca de 207 milhões de habitantes e ocupa quase metade da área que compõe a América do Sul. Está organizado sob um regime federativo em que os seus entes - os 26 estados, o Distrito Federal e os 5.570 municípios - possuem competência e autonomia, inclusive para legislar em determinadas matérias afetas à educação. 0 país está dividido em cinco regiões geográficas que apresentam entre si significativas diferenças econômicas, sociais, culturais e políticas.

No que se refere à educação, o país tem um sistema público de ensino organizado nacionalmente, porém descentralizado do ponto de vista da oferta educativa, com competências compartilhadas entre os entes federativos. Conta com 2.226.423 professores que atuam nas instituições públicas de Educação Básica nas suas três etapas: Educação Infantil, Ensino Fundamental e Ensino Médio, atendendo a um público de aproximadamente 50 milhões de crianças e jovens, de acordo com o Censo Escolar de 2018. Esses professores são contratados e remunerados pelos estados e municípios, 
o que resulta em grande diversidade e desigualdade salarial e de condições de trabalho, inclusive entre aqueles que apresentam a mesma formação e titulação. Também merece destaque o fato de a infraestrutura das escolas variar muito de acordo com a capacidade financeira de cada município e estado (Oliveira, 2015).

Os nove estados que compõem a região Nordeste do país são historicamente os que apresentam dados mais preocupantes no que se refere à elevada desigualdade social do país, com repercussões diretas sobre a oferta educativa. Situação que vem se agravando após uma década de relativa melhoria.

O Brasil ficou estagnado no ranking do Índice de Desenvolvimento Humano (IDH) no último relatório do Programa das Nações Unidas para - Desenvolvimento (Pnud). Pelo terceiro ano seguido consecutivo, o país mantém a $79^{a}$ posição no levantamento que analisou 189 países. Desde 2015, está estagnado no levantamento que mede a expectativa dos anos de escolaridade dos cidadãos $(15,4)$. A média de anos de estudo do brasileiro é a mesma de 2016 (7,8) (PNUD, 2018).

Em relação à esperança de vida ao nascer, a expectativa de vida dos brasileiros passou de 75,5 anos em 2016 para 75,7, em 2017. A renda nacional bruta, também considerada na composição do referido indicador, dimensionada em dólares, teve um salto de US\$13.730 para US\$13.755. O número, porém, ainda não alcançou o valor de 2015, quando a RNB era de US\$ 14.350 ${ }^{1}$. O Brasil vem enfrentando uma crise desde 2015 que tem promovido impactos importantes na vida dos brasileiros.

Quando se observa exclusivamente a desigualdade, a situação do país é pior. O Pnud avaliou, em 151 países, o IDH "ajustado às desigualdades". Esse índice mede a perda do desenvolvimento humano devido à distribuição desigual dos ganhos do IDH. Quando esse índice foi avaliado, o Brasil perdeu 17 posições no ranking mundial, caindo de 0,759 para 0,578. Esse índice, por si só, colocaria o Brasil na categoria de "médio" desenvolvimento, diferente da que se encontra em países de IDH alto. Isso representa uma queda de 23,9\% do IDH. Entre os países da América do Sul, o Brasil é o terceiro que mais perde percentualmente nesse índice, atrás do Paraguai $(25,5 \%)$ e da Bolívia (25,8\%). No caso brasileiro, o pior índice fica com a má distribuição de renda $(0,471)$, seguida da desigualdade na educação $(0,535)$ e na expectativa de vida $(0,765)$. Ainda assim, tem o $5^{\circ}$ melhor IDH entre os países da América do Sul.

${ }^{1}$ Cf.: https://glo.bo/35CHntz. 
Com relação ao Índice de Gini, que quanto mais próximo de um mostra que a renda na região é mais concentrada, o Brasil ficou com 0,549, o mesmo resultado de 2016. De acordo com Instituto Brasileiro de Geografia e Estatística (IBGE), a concentração de renda aumentou nas regiões Norte, Nordeste, Sul e Centro-Oeste.

Ainda de acordo com o IBGE, em 2017, houve queda de 0,56\% no rendimento de todas as fontes, que inclui além dos salários, aposentadorias, pensões, benefícios sociais como Bolsa Família, passando de R $\$ 2.124$ em 2016 para $\mathrm{R} \$ 2.112$ em 2017. Nos rendimentos do trabalho, a queda foi mais intensa, de 1,36\%, ainda mais entre os que ganham menos. Entre os $50 \%$ mais pobres, o recuo foi de 2,45\%. Essa massa de 43,4 milhões de trabalhadores passou a ganhar R \$754, valor 20\% menor que o salário mínimo do ano anterior de $\mathrm{R} \$ 937$.

O IBGE (2017) mostra ainda que a renda brasileira se mostra altamente concentrada. Juntos, os 10\% mais ricos do país recebem o mesmo que os $80 \%$ mais pobres da população. Com isso, 12,4 milhões de pessoas concentram a renda equivalente a de quase 100 milhões de pessoas $(99,6$ milhões). Os que estão no topo da pirâmide de renda, o $1 \%$ mais rico, manteve sua distância dos $50 \%$ mais pobres. Eles recebem 36,1 vezes mais que $50 \%$ da população. No Nordeste, essa distância é ainda maior, chegando a 44,9 vezes.

\section{A NGP e a circulação de políticas de educação}

A NGP começou a se implantar no Brasil durante os anos 1990. A transposição do modelo para a realidade brasileira como administração pública gerencial foi defendida como uma mudança de estratégia na gerência, posta em prática por uma estrutura administrativa reformada (Bresser-Pereira, 1999). O processo de privatização estabeleceu novo comportamento entre o cidadão e a oferta de bens e serviços essenciais, que passou a ser ditada por uma dinâmica de mercado. Por outro lado, a reorientação na condução das políticas sociais veio acompanhada da focalização da oferta e da descentralização, que no caso específico da educação ocorreu nas dimensões administrativa, financeira e pedagógica (Oliveira, 2015).

Passados cerca de 30 anos, constata-se ampla disseminação do sentido da chamada racionalização da gestão pública por meio da incorporação de modelos empresariais. Demazière, Lessard e Morrissete (2013), consideram que a NGP resulta da sedimentação progressiva de novas maneiras de pensar a organização administrativa, a importação de práticas da administração 
privada, dos ensinamentos tirados da experimentação conduzida nos países anglo-saxões e de preconização de organismos internacionais tais como a Organização para Cooperação e Desenvolvimento Econômico (OCDE). Alguns de seus princípios podem ser observados nas reformas que ocorreram nas últimas décadas em diferentes contextos nacionais, sendo eles: a dissociação das funções de execução e controle; a fragmentação das burocracias e sua abertura às demandas dos usuários; a concorrência de atores públicos com o setor privado e a terceirização dos serviços; o reforço das responsabilidades e da autonomia dos níveis de execução da ação pública; a gestão por resultados fundada na realização dos objetivos e da avaliação de desempenho; a normalização das práticas profissionais baseadas em evidências.

A NGP ganha força em muitos países no mundo por se apresentar como uma resposta às críticas à inoperância da burocracia estatal, à pouca eficiência dos serviços públicos, em especial aos problemas causados pela excessiva rigidez e padronização desses procedimentos. Ela se desenvolve assim no período ao qual o neoliberalismo se apresenta como alternativa política à direita para contrapor-se ao Estado de Bem-Estar Social.

É nesse contexto que a NGP se instaura como a possibilidade de refazer o contrato entre Estado e sociedade, propondo maior envolvimento da comunidade. Esses contratos são monitorados por meio de prestação de contas pressupondo um envolvimento responsável dos agentes, já que implicam em estabelecimento de metas e prestação de contas do que foi acordado. As avaliações são utilizadas tanto para estabelecer metas quanto para medir os progressos obtidos. Esse processo de contratualização na educação pública acaba por instituir um sistema de responsabilização. Por sistema de responsabilização é possível designar o conjunto de políticas e práticas que - Estado usa para medir e responsabilizar escolas por elevar o desempenho dos alunos e para estimular e apoiar a melhoria quando necessário.

De acordo com Anderson (2005), no campo da educação, existem três tipos principais de sistema de responsabilização: (a) cumprimento de regulamentos, (b) adesão a normas profissionais e (c) resultados impulsionados. Os sistemas de responsabilização das escolas operam de acordo com um conjunto de princípios e usam uma variedade de estratégias de implementação. A autora argumenta que os sistemas de responsabilização não são novos; para ela, as diferenças entre os sistemas atuais e aqueles empregados anteriormente são questões de "para quê" e "para quem". Baseando-se na realidade norte-americana, a autora afirma que os professores têm trabalhado principalmente dentro de três sistemas de responsabilização, muitas vezes simultaneamente. 
0 primeiro sistema exige conformidade com os estatutos e regulamentos. Os sistemas de conformidade veem a escola como a personificação de processos constantes e permitem a variação de resultados, geralmente atribuída às características variáveis dos alunos. Os professores são responsáveis pela adesão às regras perante a burocracia. 0 segundo sistema baseia-se na adesão às normas profissionais. Embora não seja obrigatório nem exigido, o impacto do amplo acordo sobre certos princípios e práticas tem feito muito para elevar a educação como uma profissão. 0 terceiro sistema de prestação de contas seria aquele baseado em resultados definidos em termos de aprendizado do aluno. Esse sistema surgiu do crescente envolvimento político na educação. Nesses sistemas, os professores são responsáveis pela aprendizagem dos alunos e prestam contas ao público em geral (Anderson, 2005).

Para a autora, os professores frequentemente se encontram respondendo aos três sistemas, tentando equilibrar os requisitos de cada um. As normas profissionais complementam os sistemas de conformidade e recuperação. Os sistemas de conformidade e resultados geralmente entram em conflito. Parte desse conflito decorre do fato de que o surgimento de sistemas de resultados tem sido fomentado pela insatisfação com resultados históricos com os sistemas de conformidade. Atualmente, os sistemas de prestação de contas se concentram menos na conformidade e mais nos resultados.

Os sistemas de responsabilização têm crescido no mundo a partir da segunda metade do século XX, em razão do desenvolvimento de sistemas comparativos de avaliação em larga escala em âmbito internacional que passaram a ser os definidores do nível de qualidade educacional dos diferentes países. Os exames internacionais têm funcionado como instrumentos de circulação e transferências de políticas educacionais em âmbito internacional, com destaque para o PISA (Carvalho, 2011).

Para Oliveira e Pal (2018), os estudos sobre transferência, difusão e circulação de políticas são um campo para a inovação na análise de políticas públicas. Os autores argumentam que, no mundo globalizado, a política pública viaja transnacionalmente, difundindo políticas que conectam naturalmente a política doméstica à internacional. Constatam que o papel dos agentes de transferência como indivíduos, think-tanks, atores não governamentais e organizações internacionais têm sido explorado em profundidade pelos estudos e pesquisas.

No caso específico da educação, a OCDE tem desempenhado papel crucial nessa circulação, desenvolvendo estudos e pesquisas, produzindo e acumulando um vasto conhecimento sobre a educação no mundo e em diferentes países (Popkewitz \& Linblad, 2016; Grek, 2016). Os instrumen- 
tos produzidos pela OCDE têm se consolidado como importante fonte de informação e ao mesmo tempo referência para os países orientarem suas políticas de educação.

\section{Políticas de avaliação em contexto de desigualdade}

Alguns municípios e estados brasileiros têm desenvolvido sistemas próprios de avaliação que exprimem uma visão restrita do processo educacional, tendo como foco a aprendizagem dirigida para os testes, avaliando os professores por meio dos resultados dos estudantes, desconsiderando as especificidades dos públicos escolares e as necessidades dos sujeitos, bem como sua formação socio-histórica.

Berliner (2013), referindo-se à realidade norte-americana, manifesta sua preocupação com a tendência generalizada nas políticas de avaliação adotadas em seu país de considerar os resultados de testes padronizados, sem levar em consideração o contexto, para determinar o valor e mérito de escolas e professores. Observa que essa é uma tendência que está se espalhando rapidamente no mundo industrializado, políticos e empresários que influenciam ou controlam a educação querem uma ciência que tenha números.

Normand (2008) afirma que a compreensão da predominância desse modelo educacional reporta aos debates sobre justiça em educação. Para ele, os princípios da filosofia política de Rawls teriam sido largamente utilizados para afirmar a tese da equidade e para dar legitimidade à igualdade dos resultados ou dos conhecimentos escolares contra uma concepção considerada retrógrada ou ideológica de igualdade de oportunidades, até então hegemônica. A utilização da teoria de justiça de Rawls, que tinha no seu cerne o princípio da diferença, teria auxiliado na construção de modelos de análise da eficácia, à medida que se desenvolviam técnicas de tratamento de informação cada vez mais sofisticadas e os bancos de dados internacionais (Normand, 2008); transformando-se, desde então, em dispositivos de governação dos sistemas educativos.

Essa concepção estaria na base dos modelos educacionais que têm priorizado a performance dos sistemas educativos. Esses modelos teriam se originado nos EUA entre os anos 1970, conforme Normand (2008), quando as pesquisas estatísticas demonstraram que as causas do insucesso escolar não deveriam ser procuradas no meio social dos alunos, mas sim nas condições de funcionamento dos estabelecimentos de ensino. Tem-se aí o surgimento 
do paradigma da eficácia escolar, amparada pela racionalização da despesa pública, tornando-se o pilar da reflexão de inúmeros estados e organizações internacionais em políticas educacionais.

Apesar da igualdade de resultados ser para seus defensores a única opção viável de compensar e reverter as desigualdades iniciais, rompendo com os determinismos sociais (López, 2005), ao focarem-se nos resultados dos testes dos alunos, deixam de considerar inúmeros fatores que envolvem o julgamento do desempenho docente.

Para Berliner (2013), a inclinação para o científico em um processo de avaliação não é ruim; é a exigência de que tudo seja quantificado é que é tola e prejudicial. Insiste que o importante é desenvolver fundamentação para fortalecer um argumento e também para fazer uma avaliação sensata e justa.

\subsection{A busca pela igualdade de resultados}

A partir de estudo documental sobre as principais regulamentações nesses estados, estudos e pesquisas nacionais e internacionais que contribuem para a compreensão das dimensões contextuais e estruturais da Educação Básica da região Nordeste do Brasil, pretende-se, neste tópico, analisar como as políticas adotadas pelos estados mais desiguais do país buscam a melhoria da educação.

O levantamento documental foi realizado a partir de um roteiro único que orientou a recolha dos dados, permitindo comparar as diferentes realidades estaduais, buscando identificar os principais aspectos que caracterizam suas redes de ensino e as orientações político-pedagógicas. Obteve-se um mapeamento do atual desenvolvimento da Educação Básica na região Nordeste, por meio de levantamento das normativas de políticas educacionais em cada estado, dados estatísticos disponíveis e revisão de literatura.

Nossa análise destaca a forte presença das políticas de avaliação como característica comum nos nove estados como estratégia para a melhoria da educação. Independentemente da composição político-partidária dos governos estaduais, a política de avaliação adotada segue a orientação nacional de alcançar as médias do Ideb, estabelecendo na maioria dos estados também seus próprios sistemas de avaliação.

A presença de políticas orientadas pela NGP suportadas por sistemas próprios de avaliação nesses estados, incluindo aqueles governados por partidos progressistas, chama atenção. Observa-se, nesses casos, paradoxo 
entre as políticas defendidas pelos movimentos sociais e aquelas de orientação tecno-burocrática baseadas na busca da eficiência capitalista e da prestação dos serviços públicos.

As avaliações têm forte presença nas políticas dos nove estados, mas a forma de conduzi-las varia consideravelmente. Foi possível identificar pelo menos três formas de condução das políticas de avaliação nesses estados. Procedemos a uma classificação em três grupos de estados de acordo com as políticas de responsabilização que desenvolvem.

\subsubsection{Sistemas de alta responsabilização}

O primeiro grupo seria composto por estados que desenvolvem políticas de alta responsabilização, adotando estratégias de bonificação e premiação pelos resultados alcançados tanto para os professores quanto para os estudantes: Ceará, Paraíba e Pernambuco.

O Ceará possui sistema próprio de avaliação de desempenho escolar desde 1992, trata-se do Sistema Permanente de Avaliação da Educação Básica do Ceará (SPAECE). Sua abrangência se deu de forma gradativa, mas, desde 2003, foi universalizada para toda a rede pública estadual e municipal. Em 2007, foi lançado o SPAECE ALFA, que passou a compreender a avaliação de leitura dos estudantes do $2^{\circ}$ ano do Ensino Fundamental. Já em 2010, diversificou-se mais ainda, passando a avaliar as diferentes etapas e modalidades de ensino (Fundamental - anos iniciais e finais; Médio $-1^{\circ}, 2^{\circ}$ e $3^{\circ}$ séries; Educação de Jovens e Adultos - anos finais do Ensino fundamental e Ensino Médio) (Pinheiro \& Benevides, 2019).

Tanto o SPAECE quanto o SPAECE-ALFA são realizados por instituição externa. O Centro de Políticas Públicas e Avaliação da Educação da Universidade Federal de Juiz de Fora (CAEd/UFJF) tem realizado o processo avaliativo. A presença do CAEd na região merece atenção.

Para os estudantes com proficiência satisfatória - a nota no patamar adequados, é oferecido um notebook como "bônus". Já para os professores e funcionários das escolas com $80 \%$ de participação dos alunos e $10 \%$ de crescimento em Língua Portuguesa e Matemática, é garantido um acréscimo em sua remuneração como $14^{\circ}$ salário.

O Programa Professor Aprendiz, apresentado como política de formação em serviço que valoriza os saberes e experiências dos professores que têm boas práticas, reconhece, através de gratificação financeira, o trabalho 
dos profissionais da educação em atividade nas escolas que alcançarem as metas anuais de evolução de aprendizagem dos alunos do Ensino Médio (Pinheiro \& Benevides, 2019).

Pernambuco com o Programa de Modernização da Gestão Pública, Metas para Educação e o Pacto pela Vida, que objetiva a melhoria do cenário educativo com o avanço nos indicadores, instaura a Política de Responsabilização Educacional. Instituída em 2007, e ainda em vigor, estabelece a obrigação do poder executivo em monitorar e dar ampla divulgação aos indicadores educacionais de desempenho de cada escola da rede estadual, bem como as metas estabelecidas para os quatro anos subsequentes.

Pernambuco conta com um sistema próprio de avaliação, Sistema de Avaliação Educacional de Pernambuco (SAEPE), criado em 2000, "com o objetivo de fomentar mudanças na educação, vislumbrando a oferta de um ensino de qualidade"2. Em 2008, o programa foi reestruturado, passando a realizar edições anuais em que são avaliados, aproximadamente, 350 mil estudantes. 0 monitoramento da gestão educacional no estado tem sido feito com base nos resultados dos estudantes, nos testes de Língua Portuguesa e Matemática ${ }^{3}$, ao final das etapas de escolaridade correspondentes à $2^{\text {a }}$ série $/ 3^{\circ}$ ano, $4^{a}$ série $/ 5^{\circ}$ ano e $8^{a}$ série $/ 9^{\circ}$ ano do Ensino Fundamental e $3^{\circ}$ ano do Ensino Médio e $4^{\circ}$ ano do Normal Médio.

Segundo Duarte (2019), a perspectiva contratualista presentes nos sistemas avaliativos se insere na gestão educacional pernambucana a partir de 2008, com a adoção do "Termo de Compromisso de Gestão Escolar" atrelado ao Bônus de Desempenho Educacional. Trata-se de instrumento contratual pactuado entre os dirigentes das escolas e a Secretaria de Estado da Educação de Pernambuco (SEE/PE), com o estabelecimento de metas anuais de desempenho institucional. Para ele, a SEE/PE espera que o Termo de Compromisso de Gestão Escolar que tem por objetivo garantir o comprometimento das escolas com a elevação dos indicadores educacionais corresponda ao esforço necessário para se alcançar o Índice de Desenvolvimento da Educação Básica de Pernambuco (IDEPE) estabelecido para o ano letivo.

São premiados os servidores em efetivo exercício por pelo menos seis meses (e que não tenha se afastado do trabalho por um período superior a este) que cumprirem, no mínimo, 50\% da meta projetada para a etapa. A partir daí, os valores recebidos são proporcionais ao percentual cumprimento da meta, até atingir o máximo de 100\%. Em 2009, ampliou o pagamento do

${ }^{2}$ Cf.: https://bit.ly/3b769Tv

${ }^{3} \mathrm{Em} 2016$ o $2^{\circ}$ ano do Ensino Fundamental, não mais $03^{\circ}$, passou a ser avaliado pelo SAEPE. Disponível em: https://bit.ly/35FG7Wu 
BDE para as Gerências Regionais de Ensino (GRE), tendo como objetivo a média das metas estabelecidas para o conjunto de escolas sob a jurisdição de cada GRE (Duarte, 2019).

É interessante observar como o envolvimento dos setores intermediários de regulação passam a constituir-se em estratégia para aumentar a pressão sobre as escolas e seus profissionais. Como demonstra Duarte (2019), os critérios e indicadores que orientam a avaliação de desempenho dos servidores e das GRE estão diretamente relacionados aos componentes de avaliação do SAEPE, como o desempenho dos estudantes nos testes de Língua Portuguesa e Matemática e o fluxo registrado pela taxa de aprovação.

O estado da Paraíba estabeleceu, no ano de 2012, o Sistema Estadual de Avaliação da Educação da Paraíba (Avaliando IDEPB) e criou iniciativas próprias de bonificação às escolas e seus profissionais, considerando o alcance de metas e critérios estabelecidos. O sistema se propõe a aferir a qualidade do ensino pelo desempenho dos estudantes avaliados anualmente nos testes de Língua Portuguesa e Matemática com os alunos dos $5^{\circ}$ e $9^{\circ}$ anos do Ensino Fundamental, além dos estudantes da $3^{a}$ série do Ensino Médio e do $4^{\circ}$ ano do Ensino Normal (Silva et al., 2019).

O CAEd/UFJF é o responsável pela implantação e realização do Sistema desde a sua criação, desenvolvendo ações de planejamento, elaboração, correção, divulgação dos resultados e oferta de cursos de formação continuada para técnicos e gestores da SEE/PB e para docentes. Informações sobre o IDEPB e seus resultados, desde 2012, são divulgados pelo CAEd/ UFJF, por meio de site específico (Silva et al, 2019). O "Sistema Avaliando IDEPB" definiu metas a serem alcançadas por escola, com base na Escala de Proficiência gerada nas diferentes proficiências avaliadas. Tais metas devem servir de referência para que cada unidade escolar elabore um Projeto de Intervenção Pedagógica (PIP).

O IDEPB consiste no teste aplicado aos estudantes, que têm seus resultados amplamente divulgados no estado, inclusive com a concessão de prêmios que consideram o alcance das metas previstas. A criação do PIP visa a ampliar o envolvimento dos profissionais da escola para o alcance das metas, aumentando os mecanismos de controle do trabalho, monitorado pelo Sistema de Gestão e Informação (SABER) (Silva et al., 2019).

Destacam-se também as premiações como instrumento de incentivo ao comprometimento dos professores com as metas. Os Prêmios Escola de Valor e Mestres da Educação foram instituídos no ano de 2012 e visam ao fomento, à seleção, à valorização e à premiação das práticas pedagógicas exitosas, resultantes de ações integradas e executadas por profissionais de 
educação. O Prêmio Escola de Valor concede o $14^{\circ}$ salário para todos os profissionais das escolas que comprovem melhoria do Ideb e dos índices de qualidade da educação: crescimento de matrícula, crescimento de aprovação, redução de reprovação, redução de evasão e redução de abandono (Silva et al., 2019). 0 prêmio é aberto, exclusivamente, às escolas da rede pública estadual da Educação Básica (Lei nº. 9.879, 2012).

O Prêmio Mestres da Educação concede o $15^{\circ}$ salário a professores que tenham projetos "selecionados e laureados" que comprovem as práticas desenvolvidas e o sucesso dos seus estudantes, mediante documento comprobatório da "permanência e desempenho progressivo dos estudantes envolvidos no projeto" (Secretaria de Estado de Educação da Paraíba, 2012). Somente podem concorrer ao prêmio professores da educação em efetivo exercício de suas funções em escolas da rede pública estadual da Educação Básica. A Paraíba conta com mais de $50 \%$ de professores com contratos temporários em sua rede estadual ${ }^{4}$.

O Programa Soma - Pacto pela Aprendizagem na Paraíba - foi lançado em 2017 e assimila a proposta do Governo Federal de realização de pactos entre os entes federados para o alcance de determinados objetivos, como ocorreu no Plano de Metas Compromisso Todos pela Educação, em que - Governo Federal conclamou estados e municípios para um pacto para a melhoria da qualidade da educação, com condicionalidades bem delimitadas. O Pacto é entre o governo do estado e os municípios, visando à melhoria da aprendizagem dos estudantes, também com a definição de exigências (Silva et al., 2019).

Essa iniciativa demonstra o envolvimento dos municípios com a política desenvolvida em âmbito estadual e federal, nesse caso bastante contaminada pelos princípios da NGP. Tal programa contempla ações como: I) implantação do SABER; II) Implantação de programa de Desenvolvimento Profissional - formação e certificação de gestores, sob responsabilidade do CAEd/UFJF; III) Formação de Professores Alfabetizadores, responsabilidade das universidades públicas do estado; IV) Distribuição de material didático para o ciclo de alfabetização; V) Avaliação de Desempenho de Estudantes da Rede Pública: realização de avaliações formativas e somativas para os estudantes do $1^{\circ}$ ao $3^{\circ}$ ano; do $5^{\circ}$ e do $9^{\circ}$ ano do EF, sob a responsabilidade do CAEd/UFJF; e vi) Monitoramento das Ações de Alfabetização e Letramento (Decreto $n^{\circ} .37 .234,2017$ ).

\footnotetext{
${ }^{4}$ Cf.: https://bit.ly/2WySFuB
} 
O Estado conta ainda, dentre suas estratégias de melhoria dos resultados da rede pública, com a Bolsa de Incentivo vinculada ao Sistema de Gestão de Informações para os docentes com carga horária mínima de 20 horas em sala, mediante o cumprimento de prazos e índices de eficiência, estabelecidos.

\subsubsection{Sistemas de média responsabilização}

O segundo grupo de estados são aqueles que apresentam sistema de média responsabilização, em que os estímulos à melhoria da performance não são diretamente dirigidos aos professores em forma de premiação ou sanção, mas percebe-se estratégias participativas que buscam o envolvimento e compromisso destes. Alagoas, Maranhão e Piauí compõem esse grupo.

Alagoas tem sistema próprio de avaliação, Sistema de Avaliação Educacional de Alagoas (SAVEAL), criado em 2001, e que desenvolve e aplica a Prova Alagoas aos estudantes dos $5^{\circ}$ e $9^{\circ}$ anos do Ensino Fundamental, em Língua Portuguesa e Matemática, visando sua preparação para a Prova Brasil. Em 2015 foi criado o Índice de Desenvolvimento da Educação de Alagoas (Ideal), instituído por portaria da Secretaria de Estado da Educação (SEE) ${ }^{5}$. A Avaliação da Rede Estadual de Alagoas (AREAL) foi implantada em 2012 e promove a aplicação de testes de Língua Portuguesa e Matemática e questionários contextuais com alunos do $1^{\circ}, 2^{\circ}$ e $3^{\circ}$ ano do Ensino Médio. O responsável pelo desenvolvimento do SAVEAL desde 2011 é a Avalia Educacional, empresa ligada ao grupo Santillana ${ }^{6}$.

Em novembro de 2018, foi implantado o Programa Escola 10, por meio da Lei 8.048, com a finalidade de garantir os direitos de aprendizagem dos estudantes da Educação Básica das redes públicas de Alagoas. Trata-se de uma articulação do governo do estado que envolve os municípios com o objetivo de melhorar o Ideb. O Programa tem como metas garantir que todos os alunos da rede pública estejam alfabetizados em Língua Portuguesa e Matemática até o final do $3^{\circ}$ ano do Ensino Fundamental, reduzir os índices de analfabetismo e de evasão escolar, além de diminuir a distorção idadesérie. As ações contemplam três eixos: acompanhamento pedagógico, disponibilização de materiais didáticos e a realização de avaliações periódicas.

Mais uma vez, observa-se o arranjo protagonizado pelo estado envolvendo os municípios em uma política com clara orientação de busca da eficiência escolar.

${ }^{5}$ Cf.: https://glo.bo/3bcEPTO

${ }^{6} \mathrm{Cf} .:$ https://bit.ly/2YCqGwO 
Apesar do Sistema Estadual de Avaliação do Maranhão (Seama) ter sido criado recentemente, em 20197 , Lima, Bianchini e Lima (2019) apontam que o governo do Maranhão iniciado em 2015 tem desenvolvido vários programas e ações no campo da educação voltados à melhoria do Ideb e do IDH no estado. Em relação ao Ensino Médio, desenvolve o Plano Mais IDEB, com definição de estratégias articuladas para o fortalecimento do Ensino Médio e melhoria dos índices educacionais com foco na formação continuada, no acompanhamento do rendimento e fluxo escolar, e na elevação da proficiência da aprendizagem. Na estrutura de gestão desse Plano, foi criado o Grupo de Trabalho de Avaliação como articulador da Supervisão de Avaliação. No que se refere à formação continuada, observa-se o foco nas disciplinas que são avaliadas nos testes em larga escala, por meio do desenvolvimento de formação em Língua Portuguesa e Matemática, incluindo formação de multiplicadores locais e de professores pelos multiplicadores da própria escola formados na primeira etapa. Também, desenvolveram-se Oficinas de Avaliação para professores de Língua Portuguesa e de Matemática, formação de gestores on-line e webconferências sobre a temática de avaliação.

Em relação às ações de elevação da proficiência de aprendizagem, em especial dirigidas ao Exame Nacional do Ensino Médio (ENEM), observase estratégias de estímulo à participação de estudantes no aplicativo ENEM Action (on-line), com nove meses de curso preparatório e com a realização de simulados, bem como, no curso de redação por meio de e-book; divulgação de informação e orientações do processo de inscrição; e apoio de transporte escolar em casos específicos. Por meio da Supervisão de Avaliação Educacional (SAVE), o Mais IDEB desenvolve diagnósticos para os três anos do Ensino Médio com base nas habilidades/descritores das Matrizes do Sistema Nacional de Avaliação da Educação Básica (Saeb), sendo três simulados no terceiro ano e um em cada ano anterior dessa etapa (Lima, Bianchini \& Lima, 2019).

No estado do Piauí também encontramos um sistema próprio de avaliação. A criação do Sistema de Avaliação Educacional do Piauí (SAEPI), em 2011, com a finalidade de avaliar do $6^{\circ}$ ao $9^{\circ}$ ano do Ensino Fundamental e as três séries do Ensino Médio na área de Língua Portuguesa e Matemática. Ele tem como objetivo a identificação do desenvolvimento de habilidades e competências consideradas essenciais para que os estudantes consigam avançar no processo de escolarização.

${ }^{7}$ A primeira avaliação do Seama foi aplicada em 2019 aos estudantes dos $5^{\circ}$ e $9^{\circ}$ anos do Ensino Fundamental das redes municipais e estadual, e do $3^{\circ}$ ano do Ensino Médio, da rede estadual. O Seama avalia a proficiência dos estudantes em Língua Portuguesa e Matemática e está sendo desenvolvido por meio do CAEd/UFJF. Ver mais: https://bit.ly/2YJ6gSO. 
O SAEPI funciona como uma referência para a orientação do trabalho nas escolas. De acordo com Sousa (2019), as orientações para a rede e para gestores e professores são feitas em publicações anuais na Revista Sistema. A coleção aborda alguns conteúdos comuns ao funcionamento do SAEPI e outros direcionados para cada grupo de sujeitos. Além disso, é importante notar que a SEDUC-PI oferece oficinas de apropriação de dados dos resultados do SAEPI para gerentes das GRE, diretores, coordenadores e supervisores. Além disso, há orientações sobre como os professores podem realizar atividades pedagógicas baseadas nos resultados do SAEPI, envolvendo a necessidade de "[...] rever o plano de curso e os planos de aula, verificando se o planejamento escolar estabelece um diálogo efetivo com as questões levantadas pela análise dos resultados da avaliação" (Secretaria de Estado de Educação do Piauí, 2017). Entretanto, o Estado não aplica ações de bonificação ou punição para os profissionais da educação.

\subsubsection{Sistemas de baixa responsabilização}

Por fim, podemos agrupar os três últimos estados: Bahia, Rio Grande do Norte e Sergipe, que apresentam baixa responsabilização ou ausência de responsabilização. Esse terceiro grupo se caracteriza por adotar políticas que, apesar de reconhecerem a avaliação como o indicador de qualidade da educação, não apresentam um sistema muito desenvolvido ou nem mesmo possuem avaliação, e nos quais não foram encontradas disposições normativas claras que vinculem as ações dirigidas aos professores por parte da secretaria com a perseguição dos resultados nos testes.

O estado da Bahia participa de pelo menos nove diferentes avaliações em larga escala, além de possuir seu próprio sistema de avaliação. O Sistema de Avaliação Baiano da Educação (SABE).

De acordo o site do CAEd/UFJF, no qual se encontram as informações relativas ao Programa, o desenho de avaliação constitui um estudo longitudinal que consiste na verificação da evolução do desempenho dos estudantes, ao longo dos três anos do Ensino Médio e da Educação Profissional Integrada ao Ensino Médio. O Avalie Alfa, por sua vez, avalia anualmente os estudantes do $2^{\circ}$ ano do Ensino Fundamental, nas disciplinas de Língua Portuguesa em todas as suas edições (2011, 2012 e 2013) e Matemática, nos anos de 2011 e $2012^{8}$.

O Avalie Alfa é um programa que tem o objetivo de identificar o nível de alfabetização das crianças, "tornando-se uma ferramenta importante para a tomada de decisão da equipe gestora e do professor, quanto

8 Idem. 
às intervenções administrativas e pedagógicas mais adequadas a serem realizadas pelos municípios que aderiram ao programa Todos Pela Escola"9. Este trata-se de um pacto com os municípios do estado para a melhoria do Ensino Fundamental. Na mesma direção, soma-se o "Programa Educar para Transformar: um pacto pela educação", que se constitui em um pacto para construção de uma rede de parcerias visando à qualidade da educação no estado e à alteração positiva dos indicadores de desempenho das escolas e de rendimento e proficiência dos estudantes (as cited in Souza \& Ramos, 2019). Esse programa envolve como parceiros outros atores como: o Google e a Federação de Indústrias do Estado da Bahia.

O estado do Rio Grande Norte só muito recentemente criou um sistema próprio de avaliação. O Sistema Integrado de Monitoramento e Avaliação Institucional (SIMAIS) foi criado em 2016, pela Secretaria de Estado da Educação e da Cultura do Rio Grande do Norte, com a missão de aferir, com maior precisão, a qualidade do ensino ofertado pela rede estadual de ensino. Em 2017, o SIMAIS passou a ser realizado em parceria com o CAEd/ UFJF, avaliando mais de 14 mil estudantes, tendo como foco a $3^{\mathrm{a}}$ série do Ensino Médio. Ao trabalhar as disciplinas Língua Portuguesa e Matemática o programa espera tornar-se uma valiosa ferramenta para gestores e professores, uma vez que os resultados auxiliam na produção de diagnósticos acerca da realidade escolar ${ }^{10}$.

De acordo com Cabral Neto e Castro (2019), esse sistema de avaliação, até o ano de 2018, não estava vinculado à distribuição de bônus de produtividade à escola, tampouco aos docentes pelo desempenho alcançado nos exames. Os resultados da avaliação, conforme os documentos oficiais, devem subsidiar a atuação de gestores e professores, visto que permitem a organização de diagnósticos acerca da realidade escolar, no que se refere, notadamente, ao rendimento da aprendizagem dos alunos.

O estado de Sergipe não possui sistema próprio de avaliação de estudantes em larga escala, valendo-se do Ideb para orientar suas políticas dirigidas à Educação Básica. Sendo um estado que apresenta índices muito baixos na avaliação realizada pelo Instituto Nacional de Estudos e Pesquisa Educacionais Anísio Teixeira (Inep), o governo de Sergipe mostrou-se bastante otimista com os resultados obtidos no Ideb em 2018. Do $6^{\circ}$ ao $9^{\circ}$ ano, a taxa de aprovação na rede estadual passou de $62,6 \%$ para $73 \%$, ou seja, um aumento de $10,4 \%$ no índice, o que significa também diminuição nas taxas de reprovação e abandono nos anos finais ${ }^{11}$.

\footnotetext{
${ }^{9}$ Idem.

${ }^{10}$ Cf.: https://bit.ly/35EsVB1

${ }^{11}$ Cf.: https://bit.ly/35Pyflv
} 
Entretanto, o estado possui, desde 2004, o Sistema de Avaliação Periódica de Desempenho (SAPED), desenvolvido pela Secretaria de Estado da Educação de Sergipe, com o objetivo de buscar inovação e a qualidade de ensino público estadual, possibilitando o repensar sobre as ações que estão sendo desenvolvidas pela Secretaria de Estado da Educação de Sergipe (SEE/ $\mathrm{SE}$ ), decorrente de um programa maior, denominado Programa de Qualidade de Ensino Público Estadual.

De acordo com a SEE/SE, o SAPED alinha-se entre os atuais estudos e trabalhos na área de avaliação institucional, objetiva examinar como cada profissional do magistério estadual está desempenhando seu papel, o quanto está, ou não, correspondendo ao que se espera dele na função que ocupa e qual é o impacto de seu desempenho nos resultados do ensino; funda-se no processo de avaliação de $360^{\circ}$, no qual o docente é avaliado pelos gestores escolares, por si próprio, pelos estudantes e pais dos alunos, de modo relacionado com a avaliação de desempenho do aluno, medido através de exames, e/ou com avaliação do rendimento escolar ${ }^{12}$.

\section{As diferentes formas de responsabilização}

Considerando as políticas de responsabilização como aquelas decorrentes do processo de contratualização na educação pública que tem nas avaliações em larga escala seu principal instrumento de prestação de contas, podemos afirmar que os estados que compõem a região Nordeste, ainda que em diferentes graus, em sua maioria, adotam tais políticas. Considerando ainda que por sistema de responsabilização é possível designar o conjunto de políticas e práticas que o Estado usa para medir e responsabilizar escolas por elevar o desempenho dos alunos e para estimular e apoiar a meIhoria quando necessário, podemos afirmar que o Brasil, na sua composição político-administrativa de caráter federativo, tem, em certa medida, adotado indiretamente uma política de responsabilização sobre estados, municípios e escolas, que se consumou na criação do Ideb em 2007. O Ideb medido pelo governo federal passou a ser um indicador de referência para a definição da qualidade da Educação Básica nas redes públicas municipais e estaduais em todo o país, mesmo não sendo a União a responsável direta por sua oferta.

Desde o início dos anos 1990 a cultura da avaliação veio se instalando na realidade brasileira com a criação do Saeb. O ENEM e o Ideb são alguns dos importantes indicadores que foram desenvolvidos em âmbito nacional como instrumentos de regulação da Educação Básica e que aca-

${ }^{12}$ Cf.: https://bit.ly/3frMlxv 
baram por ganhar a confiabilidade da sociedade e, sobretudo, dos governos estaduais e municipais independentemente de suas afiliações políticas. A crença na avaliação tem crescido enormemente no país nos últimos anos, o que é revelado pelo incremento dos seus instrumentos, haja vista a profusão de desenvolvimento de sistemas próprios de avaliação em muitos estados e municípios brasileiros. A legislação educacional também demonstra a grande aceitação que as avaliações em larga escala e seus indicadores têm junto a diferentes setores, como demonstrado na Lei 13.005/2014, na sua meta 7, que estabelece como critério de aferição da qualidade as proficiências do Ideb e mais especificamente a estratégia 7.11, que se referencia no PISA diretamente como a proficiência almejada como critério de qualidade a ser atingido.

Nossa tentativa neste artigo foi buscar nos estudos realizados sobre a política educacional dos estados que compõem a região Nordeste do Brasil aspectos comuns que permitissem traçar paralelos entre seus contextos educativos. Salta aos olhos a centralidade que ocupam as políticas de avaliação para a Educação Básica no país como um todo e na realidade específica desses estados, em especial, a importância que tem o Ideb como uma referência de qualidade da educação. Nesse sentido, buscamos compreender por meio dos estudos documentais como são orientadas as políticas que visam à melhoria da Educação Básica. O exercício foi de aproximação desses contextos, procurando agrupar os estados segundo alguns critérios relacionados às políticas de avaliação.

Dessa forma, chegamos a três grupos, compostos por três estados cada um como já descritos, nos quais as políticas de responsabilização se assemelham. Podemos assim considerar que três estados da região Nordeste: Ceará, Paraíba e Pernambuco adotam políticas de alta responsabilização caracterizadas como "high stakes". Nesses estados, as pontuações dos testes são usadas para determinar punições (como sanções, reduções de fundos, publicidade negativa), elogios (premiação, celebração pública, publicidade positiva), promoção ou compensação (aumentos salariais ou bônus para administradores e professores). Como afirma Anderson (2005), um teste de alto risco é qualquer teste usado para tomar decisões importantes sobre os estudantes, os professores, as escolas ou distritos, mais comumente para fins de responsabilização.

Nos seis estados restantes, encontramos a presença do que se considera "low stakes". O teste de baixo risco que envolve o uso frequente de instrumentos de avaliação que têm pouco impacto sobre a vida dos estudantes, dos professores e das escolas. 
A busca pela melhoria dos seus resultados em contexto de enorme desigualdade social como demonstrada nos estados do Nordeste tem levado à adoção por parte de seus governos de estratégias que variam desde o reforço escolar, a premiação de professores e alunos, a extensão da jornada escolar, formas de envolvimento e de participação dos profissionais e familiares na gestão escolar, entre outras. Curiosamente, constata-se que, independentemente das forças políticas que compõem os governos dos estados analisados, o Ideb é a referência de qualidade na educação, induzindo, portanto, algum grau de responsabilização.

\section{Referências}

Anderson, J. A. (2005). Accountability in Education. International Academy of Education International Institute for Educational Planning. Paris-France: UNESCO.

Berliner, D (2013). Effects of Inequality and Poverty vs. Teachers and Schooling on America's Youth. Teachers College Record ,115(12), 1-26.

Bresser-Pereira, L. C. (1999). Reflexões sobre a reforma gerencial brasileira de 1995. Revista do Serviço Público, 50(4), 5-30.

Cabral Neto, A., \& Castro, A. M. D. A. (2019). Política educacional no RN: diretrizes, trilhas percorridas e resultados. In: Grupo de Estudos sobre Política Educacional e Trabalho Docente. A educação básica pública nos estados do Nordeste - Brasil: condições de oferta e perspectivas para expansão com qualidade (Relatório de Pesquisa/2019), Belo Horizonte, MG.

Carvalho, L. M. (2011). Multirregulação, comparações internacionais e conhecimento pericial: interpelando o PISA como provedor de conhecimentos e políticas. In: Oliveira, D. A \& Duarte, A. Políticas públicas e educação: regulação e conhecimento (pp. 183206). Belo Horizonte: Fino Traço.

Constituição da República Federativa do Brasil de 1988. Disponível em: https://bit.ly/2Wa4msy

Demaziere, D., Lessard, C. \& Morrisete, J. (2013). Les effets de la Nouvelle Gestion Publique sur le travail des professionnels: transpositions, variations, ambivalences. Éducation \& Sociétés, 32.

Decreto $n^{\circ}$.37.234, de 14 de fevereiro de 2017. Cria o SOMA-Programa Pacto pela Aprendizagem na Paraíba e dá outras providências. Disponível em: https://bit.ly/3fsCSpT

Duarte, A. (2019). A construção da política educacional em Pernambuco na gestão de Paulo Câmara (2015-2018). In:... (Relatório de Pesquisa/2019)...

Gazibo, M. \& Jenson, J. (2004). La politique comparée: fondements, enjeux et aproches théoriques. Canadá: Université de Montréal.

Grek, S (2016). Atores do Conhecimento e a Construção de Novos Cenários de Governança: O Caso da Direção-Geral de Educação e Cultura da Comissão Europeia. Educação e Sociedade, 37(136), 707-726. http://dx.doi.org/10.1590/es0101-73302016166099. 
Instituto Brasileiro de Geografia e Estatística (2017). Pesquisa Nacional por Amostra de Domicílio Contínua 2017. Disponível em: https://bit.ly/3drml3s

Lima, L. N., Bianchini, A. R. \& Lima, F. C. S (2019). Educação básica no Maranhão no primeiro governo Dino: políticas e ações. In:... (Relatório de Pesquisa/2019)...

Lei $n^{\circ}$. 9.394, de 20 de dezembro de 1996. Estabelece as diretrizes e bases da educação nacional. Disponível em: https://bit.ly/2SH41vo

Lei $n^{\circ}$. 9.879, de 13 de setembro de 2012. Institui no âmbito do Poder Executivo Estadual, os Prêmios Mestres da Educação e Escola de Valor e dá outras providências. Disponível em: https://bit.ly/3fCaPEC

Lei $n^{0}$ 13.005, de 25 de junho de 2014. Aprova o Plano Nacional de Educação - PNE e dá outras providências. Disponível em: https://bit.ly/2zhLNtL

Lei $n^{\circ}$. 8.048, de 23 de novembro de 2018. Institui o Programa Escola 10 com a finalidade de garantir os direitos de aprendizagem dos estudantes da educação básica de todas as redes públicas de Alagoas, define as diretrizes gerais, e dá outras providências. Disponível em: https://bit.ly/3fuKFmS

López, N. (2005). Equidad educativa y desigualdad social: desafíos de la educación en el nuevo escenario latinoamericano. Buenos Aires: IIPE - UNESCO.

Normand, R (2008). Mercado, performance, accountability. Duas décadas de retórica reaccionária na educação. Revista Lusófona de Educação, 11, 49-76.

Oliveira, D. A. (2015). Nova Gestão Pública e governos democrático-populares: contradições entre a busca da eficiência e a ampliação do direito à educação. Educação e Sociedade, 36(132), 625-646.

Oliveira, O. P. de., \& Pal, L. A. (2018). Novas fronteiras e direções na pesquisa sobre transferência, difusão e circulação de políticas públicas: agentes, espaços, resistência e traduções. Rev. Adm. Pública, 52 (2), 199-220.

Pinheiro, C. H. L. \& Benevides, M. H. C (2019). A política educacional para a educação no estado do Ceará. In:... (Relatório de Pesquisa/2019)...

PNUD (2018). Atlas do desenvolvimento Humano no Brasil. Disponível em: https://bit.ly/3dnx1QL.

Popkewitz, T. \& Linblad, S. (2016). A fundamentação estatística, o governo da educação e a inclusão e exclusão sociais. Educação e Sociedade, 37(136), 707-726. http:// dx.doi.org/10.1590/es0101-73302016166099

Silva, A. F. et al. (2019). A política educacional para a educação básica no estado da Paraíba (2011-2018). In:... (Relatório de Pesquisa/2019)...

Secretaria de Estado de Educação da Paraíba (2012). Edital 014/2012. Prêmio Mestres da Educação.

Secretaria de Estado de Educação do Piauí (2017). SAEPI 2017. Revista do professor: Língua Portuguesa, 2. Disponível em: https://bit.ly/3foo7Eu.

Sousa, A. S (2019). A política educacional para a educação básica no estado do Piauí. In:... (Relatório de Pesquisa/2019)...

Souza, E. C. \& Ramos, M. D. P (2019). Políticas e programas para a educação básica no estado da Bahia: uma análise documental da atual gestão 2014-2018. In:... (Relatório de Pesquisa/2019)... 